\title{
The Relevance of the Middle Ages to the History of Science and Technology
}

\author{
NICHOLAS H. STENECK \\ Department of History \\ University of Michigan \\ Ann Arbor, Michigan 48109
}

Prior to the LATE nineteenth century, few scholars assigned much im-
portance to the Middle Ages when discussing the development of modern
science and technology. Most assumed that the medieval period was best seen
as a backward age whose darkness helped set out the brilliance of the Scien-
tific Revolution and Enlightenment. Beginning in the first decade of this cen-
tury, Pierre Duhem tried to change this view by presenting evidence of im-
portant scientific discoveries that were supposedly made in the fourteenth
century by Parisian and English scholastics. By the late 1920 , Charles Homer
Haskins drew back the curtains even farther with his speculations about the
importance of the renaissance of the twelfth century. ${ }^{1}$ With the renewed in-
terest in medieval science and technology that followed, the way was opened
for a critical reassessment of the relevance of the Middle Ages to the develop-
ment of our modern scientific-technological world.

However, the process of reassessment has yet to produce any consensus on the relevance of the medieval period to the scientific and technological revolutions of western society. Duhem's continuity thesis is now seen as much too optimistic. Fourteenth-century thinkers criticized elements of the Aristotelian world view, but they did not abandon it. Their teachings on astronomy did not anticipate Copernicus's contributions to astronomy, nor did they discover inertia or analytical geometry. Save for a few possible minor exceptions from astronomy, optics, and mathematics, it is difficult to point to any speculations about nature maintained in the Middle Ages that were not later overturned during the course of the Scientific Revolution.

When the notion of direct intellectual ties became untenable, scholars began looking for evidence of indirect relevance, seizing next on methodology. John $R$. Randall and Alistair Crombie tried to demonstrate that Galileo's scientific methods had been anticipated by earlier Italians and before them scholastics of the high Middle Ages, such as Robert Grosseteste and Roger Bacon. ${ }^{2}$ But again, the significance of the connection faded upon closer examination. Galileo scholars have since demonstrated that the roots of Galileo's scientific 
methods cannot easily be traced to a single tradition, such as the hypotheticodeductive method advanced by earlier scholastics, and the origins of the scholastic methods in question are themselves traceable to fundamental Aristotelian teachings.

With the rejection of both methodological and intellectual ties, historians turned to less direct connections to establish relevance for the medieval period. One way this was done was by giving a new twist to a thesis first advanced by Duhem. Duhem had argued that the ban on the teaching of some aspects of Aristotelian science in the well-known Condemnation of 1277 forced later scholastics to adopt new ideas to replace those that had been condemned. So it was, Duhem argued, that fourteenth-century scholastics anticipated Copernican astronomy when responding to the prohibition against teaching that "God could not move the world with rectilinear motion." ${ }^{3}$ Subsequent scholars, who, as mentioned, for the most part have rejected this aspect of Duhem's work, have nonetheless continued to study the response to the Condemnation of 1277 for evidence of more subtle transitions that could have paved the way for later scientific developments.

Of particular promise in this regard seems to be an intellectual distinction fourteenth-century scholastics used to get around the rigid limitations posed by the Condemnation of 1277, the distinction between God's two powers absolute and ordained. ${ }^{4}$ The theologians who promulgated the Condemnation of 1277 objected to limitations that so-called radical thinkers were placing on God, e.g. that God could not move the world with rectilinear motion. Fourteenth-century scholastics circumvented this objection by agreeing that in accordance with absolute power God could do anything, but that under the agreement of ordained power God had produced the specific world that exists, which world could not be moved in a straight line, abhorred vacuums, and was centered around a stationary earth. In this way they were able to discuss in an imaginary way things that might have or could have been, while keeping to the orthodoxy of the accepted Aristotelian world view. Some scholars believe that this compromise represents a significant step toward the Scientific Revolution. But what was the nature of that step?

Amos Funkenstein has argued that significant advances were made in the course of "absolute-power" (de potentia absoluta) arguments. Whether or not fourteenth-century thinkers ultimately accepted such arguments is not what really matters, according to Funkenstein. Rather, the significance of the de potentia absoluta argument is that in bringing the improbable into clear view and in subjecting impossibility to a critical analysis, it prepared the way for the ultimate acceptance of the improbable and impossible. He suggests, therefore, that 
we ought to pay close attention to the terms in which a theory defines "improbabilities" and, still more important, "impossibilities." The more precise the argument the likelier it is to be a candidate for future revisions. Once the impermissible assumption is spelled out with some of its consequences, it is but a matter of time and circumstances (. . .) until the truly radical alternative is reconsidered. ${ }^{5}$

There is, according to this view, still some merit to the hypothetical discussions of the fourteenth century, even if that merit does not involve directly the people advancing them. By mapping out the ground on which the battle would eventually be fought, fourteenth-century thinkers were participating, however tangentially, in the Scientific Revolution that was to follow.

Heiko Oberman and Gordon Leff believe that it is the absoluta-ordinata distinction itself that is of most importance. Both argue that the individualizing, as opposed to universalizing, thrust of the two-power distinction, combined with the fact that science operates almost exclusively in the ordained world and without the aid of revealed truths, left the study of nature in a state of relative freedom - from theology and metaphysics - in the fourteenth century and in need of developing methods of its own for discovering truth. The results, again for both Leff and Oberman, are nothing less than traditionbreaking, with the methods of modern science being established to fill the void. Interestingly, however, it is at this point that agreement between the two breaks down.

For Leff, the important methodological developments that follow are those that bring mathematics and logical procedures into the study of nature.

Now this detachment of physical theory from a predominantly metaphysical and theological context, in which it has been subordinated to wider metaphysical and theological issues, was the condition of its independent development; it enabled physical problems to be treated in their own terms by specifically physical and mathematical considerations and not as instances to illustrate metaphysical or theological questions. . . .

The significance of this development for Leff is that

. . . in the fourteenth century, for the first time, a distinctive body [of] scientific, mainly mechanical, theory arose with its own independent principles and procedures, which were self-contained and not subservient to higher nonphysical principles. It arose from the quantitative treatment, through the application of mathematics and up to a point logic, of problems which until then had been considered qualitatively under their different categories of movement, time, place, quantity, and quality.

These new quantitative methods mark the beginning, albeit inchoate, of future scientific procedure, namely, in generalizing the conclusion arrived at by 
calculation or analysis as formulae or laws to be taken as axioms on the Euclidean model and applied to physical phenomena. ${ }^{7}$

For Oberman, on the other hand, it is the experimental, not the abstract mathematical method, that develops in the wake of the absoluta-ordinata distinction.

In both theology and physics the distinction between possibility and reality helped to free man from the smothering embrace of metaphysics. Yet in physics the same distinction works itself out in a different way . . . . Whereas in theology the established order . . . is at the same time the revealed order . . . in the realm of physics the established order is the order of the established laws of nature, still to be investigated and freed from the babylonian captivity of metaphysical a priori.

In this climate there emerges before our eyes the beginnings of the new science. We see the first contours of this science in a double thrust: (1) the conscious and intellectually ascetic reduction and concentration on experientia . . . [and] (2) the discovery of the scientific role of imagination that allows for experiments. ${ }^{8}$

Thus, some agreement seems to be emerging over the belief that the medieval period may be seen as paving the way for later developments, but with the questions of "for what?" and "how?" remaining very much open to debate.

That ambiguity emerges at this point is understandable. The division between Leff and Oberman reflects a deeper rift within the history of science itself over the cause(s) of the Scientific Revolution. If scholars could agree that Galileo or Newton was more an experimenter than a speculative scientist, or the reverse, it would then be easier to decide which of the many possibilities inherent in the absoluta-ordinata distinction might have paved the way for the Scientific Revolution. However, as long as debate continues over the best way to characterize and account for the Scientific Revolution, establishing a basis for judging the relevance of the Middle Ages to the history of science will remain a difficult and uncertain task.

The problem of relevance is, moreover, further complicated by the fact that it is not at all certain that any of the frameworks or models used to characterize the transition from medieval to modern has any explanatory power. Funkenstein operates within the traditional model adopted by intellectual historians. He views the history of science as the ongoing process of advancing increasingly sophisticated descriptions of nature, resting the importance of the absoluta-ordinata distinction on the contribution it makes to generating new ideas. Leff and Oberman operate more within the methodological model, adding the key element of a critical values transformation - from universalism to particularism - which creates the demand (or opportunity) for new methods. 
The chain of events that develops under this model is first the shift in values (fourteenth century), which sets in motion the secondary chain of events (methological development, fourteenth-seventeenth centuries), which produces the Scientific Revolution.

As explanatory principles, both models have weaknesses. Neither can forecast the course of historical events. Knowing when an idea might first have been advanced, either as a tentative hypothesis or to be rejected, provides no information on when that idea will be adopted, i.e. cause a revolution. For the latter, Funkenstein readily admits one has to turn to other factors, such as "a different climate of opinion, tensions within the old theory, developments in other fields, [and/or] new factual evidence." ${ }^{\prime \prime}$ Leff and Oberman's model, even though it focuses on a more fundamental and potentially dynamic factor - $\mathrm{a}$ basic values transformation - does not account for the long delay between the transformation and its fruits. Once again, other factors would have to be brought in to explain why the potential that seems to be present in the medieval period took so long to develop.

The fact that it seems so necessary to turn to "other factors" to explain the timing and actual transformation from the potential of the medieval period to the Scientific Revolution strongly suggests, I would argue, that changes at the level of these "other factors" may be the Scientific Revolution. Certainly, it would seem worthwhile to test this hypothesis by looking in more detail at changes in these "other factors" over time, e.g. by tracing out the course of the shift from universalist (wholist) to particularist (specialized) thinking. The model that would be used for conducting such studies would assume that the essence of the Scientific Revolution is an underlying change in basic values, which is symptomatically manifest as, among other traits, changing methodologies, world views, occupational patterns, educational programs, support structures, interest priorities, and a host of other factors discussed in histories of science.

That there are complex and important values transformations taking place during the medieval period has long been recognized. Brian Stock's paper in this volume and longer study of literacy represent only one of many recent attempts to understand the priorities of persons who lived before the obvious great surge that produced the modern era. ${ }^{10}$ Lynn White has on numerous occasions advanced hypotheses on how technological thinking and technological values slowly captivated the Western mind. In particular, White has attempted to turn the traditional top-down mentality of scholars on its head and to show how technological values slowly changed the way intellectuals at the top thought about learning. ${ }^{11}$ If such studies were accompanied by a genuine recognition of their importance to a full understanding of the rele- 
vance of the Middle Ages to the history of science and technology, the extent of that relevance could, I believe, be delineated with much greater precision and meaning.

The importance of changing values during the Middle Ages did not escape the notice of those who were affected. As one commentator on the contemporary scene in the thirteenth century lamented:

The muses are silent, confounded, repelled, as if numbed by the sight of Medusa. But why, you ask? If you are a real scholar you are thrust out in the cold. Unless you are a money-maker, I say, you will be considered a fool, a pauper. The lucrative arts, such as law and medicine, are now in vogue, and only those things are pursued which have a cash value. ${ }^{12}$

For those of such a practical mind, the way of the future was clear. So it was that one father advised his son who had written for more money to study the Bible: "This requires, as I was told, a great deal of money. Therefore, you would be better advised to audit the arts, . . . either physics or another lucrative science, because you will not gain great wealth if you pursue the ministry." ${ }^{13}$ The reflection of values in these two comments and the potential impact on medicine, law, and the whole structure of learning could not be clearer.

So too have modern scholars recognized the importance of deep-seated transformations on the Scientific Revolution. Jacob Bronowski argues in his Common Sense of Science:

We sometimes speak as if science has step by step squeezed other interests out of our culture, and is slowly strangling the traditional ways of thinking. Nothing of the kind. The Scientific Revolution in the seventeenth century was a universal revolution. Indeed it could not have been unless there had already been a deep change in the attitudes to everything natural and supernatural among thoughtful men. Puritanism in England and Protestant martyrdom on the Continent are the religious traces of that change; Marvel and Molière mark it in the arts, and Cromwell's revolution and the wars of Louis XIV are its political traces. Nor, of course, were these changes in the climate of mind without practical antecedents. At the bottom, all derive from the explosion of the rigid hierarchy of land and craft which was the medieval world. . . 14

For Bronowski, this "regress to first causes takes us too far from the Scientific Revolution itself." In my view, such a "regress to first causes" takes us to the very heart of the Scientific Revolution and deserves to become the focal point of considerably more scholarly attention. It is only by pursuing such studies that the true relevance of the Middle Ages to the history of science and technology can be established. 


\section{NOTES AND REFERENCES}

1. Pierre Duhem, "Un précurseur français de Copernic, Nicole Oresme," Revue générale des sciences pures et appliquées 20 (1909):866-873; and Etudes sur Léonard de Vince, 3 vols. (Paris: A. Hermann, 1906-13); Charles Homer Haskins, The Renaissance of the Twelfth Century (Cambridge, MA: Harvard University Press, 1927); see also Studies in the History of Mediaeval Science (Cambridge, MA: Harvard University Press, 1924).

2. A.C. Crombie, Augustine to Galileo: The History of Science A.D. 400-1650 (London: Falcon Press, 1952); and Robert Grosseteste and the Origin of Experimental Science (Oxford: Clarendon Press, 1953); J.H. Randall, Jr., The School of Padua and the Emergence of Modern Science (Padua: Editrice Antenore, 1961).

3. Quoted from Edward Grant, A Source Book in Medieval Science (Cambridge, MA: Harvard University Press, 1974), p. 48.

4. William J. Courtenay, "Nominalism and Late Medieval Religion," in The Pursuit of Holiness, Charles Trinkaus with Heiko Oberman, eds. (Leiden: Brill, 1974), pp. 26-66.

5. Amos Funkenstein, "On the Role of Hypothetical Reasoning in the Emergence of Copernican Astronomy and Galilean Mechanics," in The Copernican Achievement, Robert S. Westman, ed. (Berkeley, CA: University of California Press, 1975), p. 170.

6. Gordon Leff, The Dissolution of the Medieval Outlook: An Essay on Intellectual and Spiritual Change in the Fourteenth Century (New York: Harper \& Row, 1976), p. 95.

7. Jbid., p. 96.

8. Heiko A. Oberman, "Reformation and Revolution: Copernicus's Discovery in an Era of Change," in The Cultural Context of Medieval Learning, J. E. Murdoch and E.D. Sylla, eds. (Dordrecht: Reidel, 1975), pp. 408-409. The general thesis advanced by Leff and Oberman is also discussed by E.R. Woods, "Ockham on Nature and God," Thomist 37(1973): 69-87.

9. Funkenstein, ${ }^{5}$ p. 170.

10. In addition to Stock's article in this volume, pp. 7-19, see The Implications of Literacy: Written Language and Models of Interpretation in the Eleventh and Twelfth Centuries (Princeton,

NJ: Princeton University Press, 1983).

11. See "Medieval Engineering and the Sociology of Knowledge," Pactific Historical Review 44(1975):1-21; and "Medical Astrologers and Late Medieval Technology," Viator 6(1975):295-308. 12. Louis J. Paetow, ed., Two Medieval Satires on the University of Paris (Berkeley, CA: University of California Press, 1927), p. 155.

13. Charles Homer Haskins, Studies in Mediaeval Culture (Oxford: Clarendon Press, 1929), p. 25. 14. Jacob Bronowski, The Common Sense of Science (Cambridge, MA: Harvard University Press, 1953), p. 19. 